\title{
Does periodontitis affect the treatment response of biologics in the treatment of rheumatoid arthritis?
}

Masahiro Tachibana ${ }^{1}$, Yukio Yonemoto ${ }^{1}$, Koichi Okamura ${ }^{1 *}$ (D), Takahito Suto ${ }^{1}$, Hideo Sakane ${ }^{1}$, Tetsuya Kaneko ${ }^{1}$ Trang Thuy Dam ${ }^{1,2,3}$, Chisa Okura' ${ }^{1}$ Tsuyoshi Tajika', Yoshito Tsushima ${ }^{2,4}$ and Hirotaka Chikuda'

\begin{abstract}
Background: Rheumatoid arthritis (RA) and periodontitis (PD) have been suggested to share many clinical and pathological features. However, few reports have investigated the relationship between the degree of PD and the treatment response to RA.

This study aimed to examine the relationship between the extent of PD and the treatment response to biologics in RA patients using FDG-PET/CT.

Methods: Sixty RA patients (male, $n=14$; female, $n=46$; average age, 58.3 years) treated with biologic agents were included in this study. FDG-PET/CT was performed at baseline and 6 months after the initiation of biological therapy. The maximum standardized uptake value (SUVmax) was used as a representative value for the assessment of the FDG uptake in periodontal tissue and joints including the bilateral shoulders, elbows, wrists, hip, knees, and ankle joints. The Disease Activity Score (DAS) 28-CRP and the following clinical parameters were assessed: C-reactive protein (CRP), erythrocyte sedimentation rate (ESR), anti-cyclic citrullinated peptide antibody (ACPA), rheumatoid factor (RF), and matrix metalloproteinase 3 (MMP-3). The relationship between the treatment response of RA and the baseline SUVmax of the periodontal tissue was evaluated.

Results: The baseline periodontal SUVmax was related to patient age $(r=0.302, p=0.009)$ and the ACPA level $(r=$ $0.265, p=0.025)$. The DAS28-CRP, CRP, ESR, MMP-3, and joint SUVmax values were significantly decreased after 6 months of biological therapy. However, the mean periodontal SUVmax, ACPA, and RF showed no significant changes after treatment. There was a significantly negative correlation between the baseline periodontal SUVmax and the treatment response of DAS28-CRP $(r=-0.369, p=0.004)$.

Conclusion: There was a negative correlation between the extent of PD at baseline and the treatment response of RA patients who received biological therapy. The evaluation of the periodontal condition is considered to be an essential part for the management of RA.
\end{abstract}

Keywords: Periodontitis, FDG-PET/CT, Biologic therapy, Rheumatoid arthritis, Treatment response

\footnotetext{
*Correspondence: kokamura@gunma-u.ac.jp

'Department of Orthopaedic Surgery, Gunma University Graduate School of Medicine, Showa-machi 3-39-15, Maebashi, Gunma 371-8511, Japan

Full list of author information is available at the end of the article
}

(c) The Author(s). 2020 Open Access This article is licensed under a Creative Commons Attribution 4.0 International License, which permits use, sharing, adaptation, distribution and reproduction in any medium or format, as long as you give appropriate credit to the original author(s) and the source, provide a link to the Creative Commons licence, and indicate if changes were made. The images or other third party material in this article are included in the article's Creative Commons licence, unless indicated otherwise in a credit line to the material. If material is not included in the article's Creative Commons licence and your intended use is not permitted by statutory regulation or exceeds the permitted use, you will need to obtain permission directly from the copyright holder. To view a copy of this licence, visit http://creativecommons.org/licenses/by/4.0/ The Creative Commons Public Domain Dedication waiver (http://creativecommons.org/publicdomain/zero/1.0/) applies to the data made available in this article, unless otherwise stated in a credit line to the data. 


\section{Background}

In recent years, rheumatoid arthritis (RA) and periodontitis (PD) have been suggested to share many clinical and pathological features and PD is considered to be a risk factor for RA. Some previous reports indicated the increased prevalence of PD in RA patients $[1,2]$. PD causes persistent inflammation and is linked with citrullination. In RA patients, the severity of periodontal conditions was associated with both the presence and levels of anti-cyclic citrullinated peptide antibodies (ACPAs) [3]. Additionally, anti-cyclic citrullinated peptide antibody (ACPA) has been reported as an important indicator for RA treatment and is associated with erosive joint destruction $[4,5]$.

Porthyomonas gingivalis ( $P$. gingivalis) is the main causative agent of the PD and a unique bacterium that is known to express an enzyme that increases citrullination $[6,7]$. Recently, it has been reported that $P$. gingivalis can induce RA in non-smokers. PD associated with $P$. gingivalis is more likely to be present in those at risk of RA in comparison to healthy controls [8]. Furthermore, the presence of $P$. gingivalis infections may precede the clinical onset of RA by a number of years [9].

There has been no agreement on the relationship between the degree of PD and the disease activity of RA. Rodríguez-Lozano et al. reported that there was an association between the disease severity of PD and the disease activity of RA [10]. In contrast, Mobini et al. demonstrated that there was no significant relationship between the disease activity of RA and the severity of PD [11]. Additionally, it might be possible that PD affects the treatment response of RA. Savioli et al. reported that RA patients with PD showed no significant differences in disease activity parameters during 6 months of treatment with anti-tumor necrosis factor (TNF) inhibitors [12]. However, the extent of PD in their study was unknown, and the relationship between PD and the treatment response of RA has been unclear.

This study aimed to examine the relationship between the extent of PD and the treatment response in RA patients who receive biological therapy. We hypothesized that the degree of PD would be correlated with the treatment response in RA patients who receive biological therapy. To assess the degree of periodontitis, we used [18F] fluorodeoxyglucose-positron emission tomography/computed tomography (FDG-PET/CT) [13-16]. FDG-PET/CT has also been used to assess the disease activity of the RA [17-21].

\section{Materials and methods}

\section{Patients and methods}

The institutional review board of our hospital approved the study. Sixty patients (male, $n=14$; female, $n=46$; average age, $58.3 \pm 14.1$ years) were enrolled in this study (Table 1). Based on the power analysis, a sample size of
Table 1 The characteristics and the parameters of all patients at baseline and after treatment

\begin{tabular}{|c|c|c|c|}
\hline$n=60$ & Baseline & After treatment & $p^{*}$ \\
\hline Age (year) & $58.3 \pm 14.1$ & - & - \\
\hline Sex (male/female) & $14 / 46$ & - & - \\
\hline Disease duration (year) & $13.3 \pm 12.4$ & - & - \\
\hline Steinbrocker stage (I/II/III/IV) & $7 / 14 / 21 / 18$ & - & - \\
\hline Steinbrocker class (1/2/3/4) & $14 / 27 / 13 / 6$ & - & - \\
\hline Concomitant MTX (\%) & 55 & - & - \\
\hline MTX dosage (mg/week) & $8.91 \pm 2.65$ & - & - \\
\hline Concomitant PSL (\%) & 45 & - & - \\
\hline PSL dosage (mg/day) & $3.70 \pm 1.86$ & - & - \\
\hline Smoking history (\%) & 10 & - & - \\
\hline ACPA positive (\%) & 80 & - & - \\
\hline CRP (mg/dl) & $2.07 \pm 2.21$ & $0.50 \pm 1.05$ & $<0.01$ \\
\hline $\mathrm{ESR}(\mathrm{mm} / \mathrm{h})$ & $62.6 \pm 31.4$ & $35.3 \pm 27.0$ & $<0.01$ \\
\hline WBC $(/ \mu l)$ & $6610 \pm 2140$ & $5582 \pm 2067$ & $<0.01$ \\
\hline $\mathrm{RF}(\mathrm{mg} / \mathrm{dl})$ & $256.0 \pm 876.9$ & $162.7 \pm 551.9$ & 0.43 \\
\hline ACPA (U/ml) & $91.5 \pm 117.1$ & $75.2 \pm 96.1$ & 0.36 \\
\hline MMP-3 (ng/ml) & $261.30 \pm 243.82$ & $118.65 \pm 129.42$ & $<0.01$ \\
\hline DAS28-CRP & $4.07 \pm 1.23$ & $2.35 \pm 1.01$ & $<0.01$ \\
\hline Joints SUV & $2.13 \pm 0.65$ & $1.67 \pm 0.50$ & $<0.01$ \\
\hline Periodontal SUV & $1.83 \pm 0.46$ & $1.88 \pm 0.45$ & 0.39 \\
\hline
\end{tabular}

*Wilcoxon's signed-rank test

Abbreviations: MTX methotrexate, PSL prednisolone, ACPA anti-cyclic citrullinated peptide antibody, CRP C-reactive protein, ESR erythrocyte sedimentation rate, $W B C$ white blood cell, $R F$ rheumatoid factor, MMP-3 matrix metalloproteinase 3, DAS Disease Activity Score

60 patients would supply $80.4 \%$ power to detect a difference with an alpha error of 0.05 .

All patients were diagnosed according to the American College of Rheumatology (ACR) criteria revised in 1987 [22], and their previous treatment with conventional synthetic disease-modifying antirheumatic drugs (csDMARDs), including methotrexate (MTX), provided clinically inadequate responses. Thus, the patients were recommended for treatment with biological agents. The following biological agents were administered: infliximab (IFX; $n=18$ ), etanercept (ETN; $n=14$ ), adalimumab (ADA; $n=15$ ), and tocilizumab (TCZ; $n=13)$. Patients with poor control of diabetes and those with other inflammatory diseases were excluded from the analysis. The average disease duration of these patients was $13.3 \pm 12.4$ years. The concomitant MTX rate was $75 \%$, the average dose of MTX was $6.99 \pm 2.57$ $\mathrm{mg} /$ week, the concomitant prednisolone (PSL) rate was $75 \%$, and the average dose of PSL was $3.71 \pm 1.86 \mathrm{mg} /$ day. After a baseline assessment using whole-body FDG-PET/ $\mathrm{CT}$, they received biological therapies. FDG-PET/CT and clinical assessments were also performed 6 months after the initiation of therapy. The clinical assessments included measurement of the serum concentrations of C-reactive 
protein (CRP), erythrocyte sedimentation rate (ESR), matrix metalloproteinase 3 (MMP-3), ACPA, and rheumatoid factor (RF). The inflammation activity was evaluated using the Disease Activity Score (DAS) 28-CRP [23, 24].

\section{FDG-PET/CT image}

Whole-body PET was performed following the intravenous injection of $18 \mathrm{~F}-\mathrm{FDG}(5 \mathrm{MBq} / \mathrm{kg})$, after the patient had fasted for over $6 \mathrm{~h}$. Data acquisition was performed in 3D mode, $60 \mathrm{~min}$ after the injection, using a PET-CT scanner (Biograph 16; Siemens Medical Solutions Inc., Munich, Germany). Patients were scanned from head to toe in the arms-down position, according to the methods of previous reports [17-21]. PET images were interpreted by physicians, and an increased FDG uptake in periodontal tissue and joints was recorded.

To evaluate the FDG uptake in periodontal tissue, we measured the uptake in the upper posterior gingival tissue to limit spillover from pharyngeal and buccal structures [12-14] (Fig. 1).

To evaluate the FDG uptake in the joints, we measured 12 joints, including the bilateral shoulder, elbow, wrist, hip, knee, and ankle joints [17].

\section{Data analysis}

For the semiquantitative analyses, functional images of the standardized uptake value (SUV) were produced using attenuation-corrected transaxial images, the injected doses of FDG, patient's body weight, and the cross-calibration factor between PET and a dose calibrator. The SUV was defined as follows:

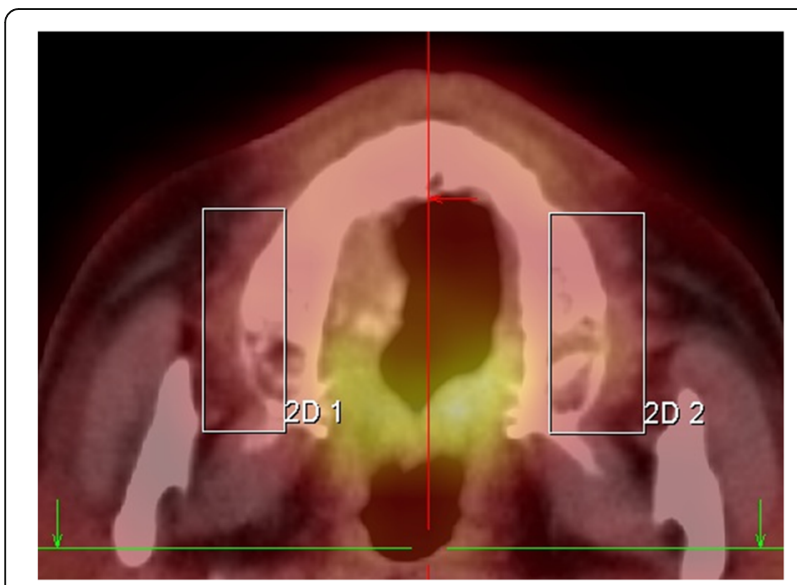

Fig. 1 Periodontal measurement using FDG-PET/CT. FDG-PET/CT images demonstrate FDG activity localized to the periodontal tissues. The boxes within the PET-CT image indicate the region of FDG activity and are drawn from the middle of the teeth toward the ipsilateral aspect of the teeth. FDG-PET/CT, 18F-fluorodeoxyglucosepositron emission tomography, and computed tomography
$\mathrm{SUV}=$ radioactive concentration in the region of interest $(\mathrm{ROI})$ $(\mathrm{MBq} / \mathrm{g}) /$ injected dose $(\mathrm{MBq}) /$ patient's body weight

ROIs were manually drawn on SUV images at each periodontal tissue and each joint including the bilateral shoulders, elbows, wrists, hip, knees, and ankle joints. The ROI analysis was conducted by a physician with the aid of corresponding CT scans. The maximal SUV (SUVmax) in the ROI was used as a representative value for the assessment of the FDG uptake.

The therapeutic response of the periodontal tissue and joints was evaluated by the changes in the mean SUVmax of the periodontal tissue and affected joints. The DAS28-CRP was also used to assess the treatment response. Periodontal SUV was defined as the mean SUVmax of the upper posterior gingival tissue. Joints SUV was defined as the mean SUVmax of the 12 joints.

In the following results section, $\Delta$ indicates the difference in the values before and after treatment.

For example, the $\triangle \mathrm{CRP}$ was defined as follows:

$$
\Delta \mathrm{CRP}=\mathrm{CRP} \text { (baseline) }-\mathrm{CRP}(\text { after treatment })
$$

\section{Statistical analysis}

We performed a power analysis using GPower 3.1. A sample size of 60 patients would supply $80.4 \%$ power to detect a difference with an alpha error of 0.05 and an effect size of 0.354. Spearman's rank correlation test and the partial correlation analyses were used to test the correlation between different parameters recorded in this study. Wilcoxon's signed-rank test was used to assess differences in treatment evaluations. The IBM SPSS Statistics 24 software program (International Business Machines Corp., New York, NY, USA) was used for the analysis. $p$ values of $<0.05$ were considered to indicate statistical significance.

\section{Results}

\section{Correlation between periodontal accumulation and RA parameters}

The correlation between the baseline periodontal accumulation and RA parameters was examined. Periodontal accumulation was correlated with the level of ACPA $(r=0.354, p=0.007)$. Age, RF, DAS28-CRP, and other parameters at baseline were not correlated with periodontal accumulation (Table 2).

\section{Changes before and after biological treatment}

We examined the change of each parameter at baseline and 6 months after the initiation of the biological therapy (Table 1). After biological therapy, the CRP, ESR, MMP-3, joint SUVmax, and DAS28-CRP values were significantly decreased; however, the mean periodontal SUVmax was not significantly changed. Similarly, the 
Table 2 Relationship between the periodontal SUV and the clinical parameters at baseline

\begin{tabular}{lll}
\hline & $r$ & $p^{*}$ \\
\hline ACPA (U/ml) & 0.354 & 0.01 \\
Age (year) & 0.206 & 0.11 \\
RF (mg/dl) & 0.073 & 0.59 \\
DAS28-CRP & -0.228 & 0.08 \\
Disease duration (year) & 0.049 & 0.72 \\
WBC (/Ml) & -0.029 & 0.83 \\
MMP-3 (ng/ml) & -0.107 & 0.43 \\
\hline
\end{tabular}

*Spearman's rank correlation test

Abbreviations: $A C P A$ anti-cyclic citrullinated peptide antibody, $R F$ rheumatoid factor, DAS Disease Activity Score, WBC white blood cell, MMP-3 matrix metalloproteinase 3

ACPA and RF values showed no significant changes from before to after treatment.

We divided the patients into two groups, the antiTNF- $\alpha$ inhibitor (IFX, ETN, ADA) treatment group and the anti-Interleukin-6 receptor inhibitor (TCZ) treatment group, and analyzed the groups in the same way. Neither group showed significant changes from before to after treatment (data not shown).

\section{Association between baseline parameters and the treatment response of RA patients who received biological therapy}

There was a significant correlation between the periodontal SUVmax at baseline and $\triangle \mathrm{DAS} 28-C R P(r=-$ $0.369, p=0.004$ ) (Table 3). As for the citrullination, there was no correlation between the value of ACPA at baseline and changes in disease activity (data not shown). We used partial correlation coefficients to examine whether other baseline parameters had any effect on the correlations between the periodontal SUVmax at baseline and $\triangle \mathrm{DAS} 28-\mathrm{CRP}$. When the value of ACPA at baseline and the smoking history were taken as the control variable, there was no significant correlation between the periodontal SUVmax at baseline and

Table 3 Relationship between the periodontal SUV at baseline and the difference in the values before and after treatment

\begin{tabular}{lll}
\hline & $r$ & $p^{*}$ \\
\hline$\triangle \mathrm{ACPA}(\mathrm{U} / \mathrm{ml})$ & 0.179 & 0.132 \\
$\Delta \mathrm{WBC}(/ \mathrm{ll})$ & -0.063 & 0.634 \\
$\Delta \mathrm{RF}(\mathrm{mg} / \mathrm{dl})$ & 0.059 & 0.659 \\
$\Delta \mathrm{MMP}-3(\mathrm{ng} / \mathrm{ml})$ & -0.211 & 0.108 \\
$\Delta \mathrm{DAS28}-\mathrm{CRP}$ & -0.369 & 0.004
\end{tabular}

*Spearman's rank correlation test

Abbreviations: ESR erythrocyte sedimentation rate, WBC white blood cell, $R F$

rheumatoid factor, ACPA anti-cyclic citrullinated peptide antibody, MMP-3

matrix metalloproteinase 3, DAS Disease Activity Score, $\Delta$ the difference in the

values between before and after treatment $\triangle \mathrm{DAS28-CRP}(r=-0.213, p=0.118$ and $r=-0.246, p=$ 0.190 , respectively) (Table 4 ).

\section{Discussion}

Some previous studies reported that ACPA was higher in patients with severe PD in both RA and non-RA patients $[6,7]$. The results of this study also showed a correlation between the periodontal accumulation of FDG and the level of ACPA (Table 2), suggesting that there was a relationship between periodontal disease and citrullination.

Regarding the use of FDG-PET/CT for the evaluation of periodontal disease, ${ }^{18} \mathrm{~F}$-FDG is actually an excellent tracer for the detection of inflammation. Some human studies have demonstrated that useful information about the inflammation of a cavity can be obtained in addition to the detection of primary tumors, metastatic disease, and lymph node metastasis [13, 16, 24, 25]. The density of ${ }^{18} \mathrm{~F}$-FDG is proportional to the degree of inflammation from oral infections [25].

A recent meta-analysis revealed the association between periodontitis and RA [26]. Rodríguez-Lozano et al. demonstrated that the severity of periodontitis was significantly associated with RA disease activity [10]. Because RA severity and the condition of PD are associated, therapy for one disease has potential to treat the other disease.

To date, the effect of biologics on PD has been investigated. A previous prospective study from France demonstrated that the periodontal parameters of 40 RA patients became worse with 33.9 months of IFX therapy [27]. Recently, Rinaudo-Gaujous et al. indicated that IFX therapy slightly increased concentrations of antibodies against $P$. gingivalis [28]. On the other hand, they recently reported that the periodontal parameters of RA patients $(n=21$, average disease duration, 14 years) was improved after 6 months of anti-B lymphocyte therapy [29].

Table 4 Partial correlations between the periodontal SUVmax at baseline and $\triangle$ DAS28-CRP

\begin{tabular}{lll}
\hline Control variables & & $\Delta$ DAS28-CRP \\
\hline Age (year) & $r$ & -0.288 \\
& $p$ & 0.027 \\
Disease duration (year) & $r$ & -2.777 \\
RF (mg/dl) & $p$ & 0.005 \\
Smoking history & $r$ & -0.27 \\
& $p$ & 0.043 \\
ACPA (U/ml) & $r$ & -0.246 \\
& $p$ & 0.19 \\
& $r$ & -0.213 \\
RF & $p$ & 0.118 \\
\hline
\end{tabular}

$R F$ rheumatoid factor, $A C P A$ anti-cyclic citrullinated peptide antibody 
Marotte summarized these previous studies. TNF blocker treatment worsens the gingival inflammation, but decreases the gingival destruction of bone. In contrast, B cell blocker or IL-6 receptor blockers decreased the gingival inflammation or gingival bone destruction related to the PD [30-32]. In our study, there was no significant change in the periodontal accumulation of FDG from before to after biological treatment. Furthermore, there was no significant difference in the PD activity between the anti-TNF therapy group and the anti-IL6 therapy group in our study. These data indicated that biological treatment, including anti-TNF and anti-IL6 receptor therapy, might not improve the periodontal disease activity of RA patients and that the difference in the mechanisms of biologic agents did not influence the disease activity of PD although further study should be undertaken to evaluate the effect of biologics on the condition of PD.

As for the treatment responses of RA patients with or without $\mathrm{PD}$, a recent prospective study demonstrated that 6 months of treatment with an anti-TNF $\alpha$ inhibitor (IFX) did not improve the disease activity of RA in patients with PD; however, the disease activity of RA of the patients without PD was decreased by 6 months of IFX treatment [12]. Since they did not directly compare these two groups, and the extent of PD had not been investigated, the influence of PD on the treatment response of RA had not been understood. In our study, we evaluated the degree of periodontal inflammation according to the accumulation of FDG. The results of this study showed a negative correlation between the periodontal accumulation of FDG before biological treatment and the change of DAS28-CRP. These results indicated that the condition of periodontitis, which was associated with the ACPA levels, affected the treatment response of RA. It was considered that the poorer the PD state was, the less effective the biological treatment. Therefore, treatment intervention for PD might be worthwhile for improving the therapeutic response of patients with RA.

Another point is that the PD severity itself might affect the disease activity of RA. Some previous studies suggested that the treatment of PD could improve RA outcomes [33-35]. However, the ESPERA randomized controlled trial [36] recently concluded that periodontal treatment led to periodontal health, but no significant effects on the DAS28-ESR [37]. At any rate, good dental hygiene is important for RA patients.

Our study was associated with some limitations. First, periodontitis was evaluated based on the accumulation of FDG and the periodontal condition was not checked by a dentist. Second, we only evaluated patients with RA; there was no control group. Third, the FDG uptakes of the hand joints were not assessed in this study since the method used in this study was not suitable for measurement of the hands. With a special device, the hands should be scanned separately with the patient in the prone position.

\section{Conclusion}

There was a negative correlation between the extent of $\mathrm{PD}$ at baseline and the treatment response of RA in patients who received biological therapy. Therefore, the condition of periodontitis might affect ACPA levels and the treatment response of RA. The evaluation of periodontal condition is considered an essential part for the management of RA.

\section{Abbreviations}

$\Delta$ : Differences in the values before and after treatment; ACPA: Anti-cyclic citrullinated peptide antibody; ACR: American College of Rheumatology; ADA: Adalimumab; CRP: C-reactive protein; csDMARDs: Conventional synthetic disease-modifying antirheumatic drugs; DAS: Disease activity score; ESR: Erythrocyte sedimentation rate; ETN: Etanercept; FDG-PET/ $C T$ : Fluorodeoxyglucose-positron emission tomography/computed tomography; IFX: Infliximab; MMP-3: Matrix metalloproteinase 3; MTX: Methotrexate; PD: Periodontitis; P. gingivalis: Porthyomonas gingivalis; PSL: Prednisolone; RA: Rheumatoid arthritis; RF: Rheumatoid factor; ROI: Region of interest; SUV: Standardized uptake value; SUVmax: Maximum standardized uptake value; TCZ: Tocilizumab; TNF: Tumor necrosis factor

\section{Acknowledgements}

The authors thank Nobuhiro Tahara in Kurume University School of Medicine for his contributions to the evaluation of the FDG uptake in this study.

\section{Authors' contributions}

MT, YY, and KO made substantial contributions to the design of the study, acquisition, analysis, interpretation of data, and writing of the manuscript. YY and $\mathrm{KO}$ participated in the design of the study, acquiring data, helped to draft the manuscript, and contributed to revising the manuscript critically. TS, HS, TK, DTT, and CO participated in acquiring data and critically contributing to revising the manuscript. $T$ critically contributed to revising the manuscript enhancing its intellectual content. YT and $\mathrm{HC}$ participated in approving the final content of the manuscript. All authors read and approved the final manuscript.

\section{Funding}

There has been no significant financial support for this work that could have influenced its outcome. The authors acknowledge the financial support provided by a UCB Japan Grant (UCBJ Grant) for the English proofreading and article processing charge of the journal.

Availability of data and materials

All data generated or analyzed during this study are included in this published article and its supplementary information file.

\section{Ethics approval and consent to participate}

Ethical approval was obtained from the institutional review board of the Gunma University Hospital. Patients provided written informed consent before taking part in this study.

\section{Competing interests}

The authors declare that they have no competing interests.

\section{Author details}

'Department of Orthopaedic Surgery, Gunma University Graduate School of Medicine, Showa-machi 3-39-15, Maebashi, Gunma 371-8511, Japan. ${ }^{2}$ Department of Diagnostic Radiology and Nuclear Medicine, Gunma University Graduate School of Medicine, Showa-machi 3-39-15, Maebashi, Gunma 371-8511, Japan. ${ }^{3}$ Radiology Center, Bach Mai Hospital, Hanoi, Vietnam. ${ }^{4}$ Research Program for Diagnostic and Molecular Imaging, Division of Integrated Oncology Research, Gunma University Initiative for Advanced Research (GIAR), Maebashi, Gunma, Japan. 
Received: 16 April 2020 Accepted: 13 July 2020 Published online: 25 July 2020

\section{References}

1. Ziebolz D, Pabel SO, Lange K, Krohn-Grimberghe B, Hornecker E, Mausberg RF. Clinical periodontal and microbiologic parameters in patients with rheumatoid arthritis. J Periodontol. 2011;82(10):1424-32.

2. Hashimoto M, Yamazaki T, Hamaguchi M, Morimoto T, Yamori M, Asai K, Isobe Y, Furu M, Ito H, Fujii T, et al. Periodontitis and Porphyromonas gingivalis in preclinical stage of arthritis patients. PLoS One. 2015;10(4): e0122121.

3. González-Febles J, Rodríguez-Lozano B, Sánchez-Piedra C, Garnier-Rodríguez J, Bustabad S, Hernández-Gonzálezet M, et al. Association between periodontitis and anti-citrullinated protein antibodies in rheumatoid arthritis patients: a cross-sectional study. Arthritis Res Ther. 2020;22(1):27.

4. Schellekens GA, Visser $H$, de Jong BA, van den Hoogen FH, Hazes JM, Breedveld FC, van Venrooij WJ. The diagnostic properties of rheumatoid arthritis antibodies recognizing a cyclic citrullinated peptide. Arthritis Rheum. 2000;43(1):155-63.

5. Agrawal S, Misra R, Aggarwal A. Autoantibodies in rheumatoid arthritis: association with severity of disease in established RA. Clin Rheumatol. 2007; 26(2):201-4.

6. Leech MT, Bartold PM. The association between rheumatoid arthritis and periodontitis. Best Pract Res Clin Rheumatol. 2015;29(2):189-201.

7. Terao C, Asai K, Hashimoto M, Yamazaki T, Ohmura K, Yamaguchi A, Takahashi K, Takei N, Ishii T, Kawaguchi T, et al. Significant association of periodontal disease with anti-citrullinated peptide antibody in a Japanese healthy population - the Nagahama study. J Autoimmun. 2015;59:85-90.

8. Mankia K, Cheng Z, Do T, Hunt L, Meade J, Kang J, et al. Prevalence of periodontal disease and Periodontopathic Bacteria in anti-cyclic citrullinated protein antibody-positive at-risk adults without arthritis. JAMA Netw Open. 2019;2(6):e195394.

9. Johansson L, Sherina N, Kharlamova N, Potempa B, Larsson B, Israelsson L, et al. Concentration of antibodies against Porphyromonas gingivalis is increased before the onset of symptoms of rheumatoid arthritis [published correction appears in Arthritis Res Ther. 2016 Nov 4;18(1):257]. Arthritis Res Ther. 2016;18(1):201.

10. Rodríguez-Lozano B, González-Febles J, Garnier-Rodríguez JL, Dadlani S, Bustabad-Reyes S, Sanz M, Sánchez-Alonso F, Sánchez-Piedra C, GonzálezDávila E, Díaz-González F. Association between severity of periodontitis and clinical activity in rheumatoid arthritis patients: a case-control study. Arthritis Res Ther. 2019;21(1):27.

11. Mobini M, Maboudi A, Ali Mohammadpour R. Periodontitis in rheumatoid arthritis patients, abundance and association with disease activity. Med J Islam Repub Iran. 2017;31:44.

12. Savioli C, Ribeiro AC, Fabri GM, Calich AL, Carvalho J, Silva CA, Viana VS, Bonfá E, Siqueira JT. Persistent periodontal disease hampers anti-tumor necrosis factor treatment response in rheumatoid arthritis. J Clin Rheumatol. 2012;18(4):180-4.

13. Kito S, Koga H, Kodama M, Yamamoto N, Kokuryo S, Habu M, Matsuo K, Nishino T, Kubota K, Muraoka K, et al. Reflection of ${ }^{18} \mathrm{~F}-\mathrm{FDG}$ accumulation in the evaluation of the extent of periapical or periodontal inflammation. Oral Surg Oral Med Oral Pathol Oral Radiol. 2012;114(6):e62-9.

14. Fifer KM, Qadir S, Subramanian S, Vijayakumar J, Figueroa AL, Truong QA, Hoffmann U, Brady TJ, Tawakol A. Positron emission tomography measurement of periodontal 18F-fluorodeoxyglucose uptake is associated with histologically determined carotid plaque inflammation. J Am Coll Cardiol. 2011;57(8):971-6.

15. Subramanian S, Emami H, Vucic E, Singh P, Vijayakumar J, Fifer KM, Alon A Shankar SS, Farkouh M, Rudd JHF, et al. High-dose atorvastatin reduces periodontal inflammation: a novel pleiotropic effect of statins. J Am Coll Cardiol. 2013;62(25):2382-91.

16. Shimamoto H, Tatsumi M, Kakimoto N, Hamada S, Shimosegawa E, Murakami S, Furukawa S. Hatazawa J: (18) F-FDG accumulation in the oral cavity is associated with periodontal disease and apical periodontitis: an initial demonstration on PET/CT. Ann Nucl Med. 2008;22(7):587-93.

17. Okamura K, Yonemoto Y, Arisaka Y, Takeuchi K, Kobayashi T, Oriuchi N, Tsushima $Y$, Takagishi $K$. The assessment of biologic treatment in patients with rheumatoid arthritis using FDG-PET/CT. Rheumatology (Oxford). 2012; 51(8):1484-91.
18. Okamura K, Yonemoto Y, Okura C, Higuchi T, Tsushima Y, Takagishi K. Evaluation of tocilizumab therapy in patients with rheumatoid arthritis based on FDG-PET/CT. BMC Musculoskelet Disord. 2014;15:393.

19. Yonemoto Y, Okamura K, Takeuchi K, Kaneko T, Kobayashi T, Okura C, Tsushima Y. Takagishi K: [18F] fluorodeoxyglucose uptake as a predictor of large joint destruction in patients with rheumatoid arthritis. Rheumatol Int. 2016;36(1):109-15.

20. Suto T, Okamura K, Yonemoto Y, Okura C, Tsushima Y, Takagishi K. Prediction of large joint destruction in patients with rheumatoid arthritis using 18F-FDG PET/CT and disease activity score. Medicine (Baltimore). 2016;95(7):e2841.

21. Suto T, Yonemoto $Y$, Okamura K, Okura C, Kaneko T, Kobayashi T, Tachibana M, Tsushima Y, Takagishi K. Predictive factors associated with the progression of large-joint destruction in patients with rheumatoid arthritis after biologic therapy: a post-hoc analysis using FDG-PET/CT and the ARAS $\mathrm{HI}$ (assessment of rheumatoid arthritis by scoring of large-joint destruction and healing in radiographic imaging) scoring method. Mod Rheumatol. 2017;27(5):820-7.

22. Arnett FC, Edworthy SM, Bloch DA, McShane DJ, Fries JF, Cooper NS, Healey LA, Kaplan SR, Liang MH, Luthra HS. The American Rheumatism Association 1987 revised criteria for the classification of rheumatoid arthritis. Arthritis Rheum. 1988;31(3):315-24.

23. Smolen JS, Landewé RBM, Bijlsma JWJ, Burmester GR, Dougados M, Kerschbaumer A, et al. EULAR recommendations for the management of rheumatoid arthritis with synthetic and biological disease-modifying antirheumatic drugs: 2019 update. Ann Rheum Dis. 2020;79(6):685-99. https://doi.org/10.1136/annrheumdis-2019-216655. Epub 2020 Jan 22. PMID: 31969328

24. Spriet M, Willcox JL, Culp WTN. Role of positron emission tomography in imaging of non-neurologic disorders of the head, neck, and teeth in veterinary medicine. Front Vet Sci. 2019;6:180. Published 2019 Jun 11.

25. Yamashiro K, Nakano M, Sawaki K, Okazaki F, Hirata Y, Takashiba S. The potential of positron emission tomography/computerized tomography (PET/CT) scanning as a detector of high-risk patients with oral infection during preoperative staging. Oral Surg Oral Med Oral Pathol Oral Radiol. 2016;122:242-9.

26. Fuggle NR, Smith TO, Kaul A, Sofat N. Hand to mouth: a systematic review and meta-analysis of the association between rheumatoid arthritis and periodontitis. Front Immunol. 2016;7:80. Published 2016 Mar 2. https://doi. org/10.3389/fimmu.2016.00080.

27. Pers JO, Saraux A, Pierre R, Youinou P. Anti-TNF-alpha immunotherapy is associated with increased gingival inflammation without clinical attachment loss in subjects with rheumatoid arthritis. J Periodontol. 2008;79(9):1645-51.

28. Rinaudo-Gaujous M, Blasco-Baque V, Miossec P, Gaudin P, Farge P, Roblin X, et al. Infliximab induced a dissociated response of severe periodontal biomarkers in rheumatoid arthritis patients. J Clin Med. 2019;8(5):751.

29. Coat J, Demoersman J, Beuzit S, Cornec D, Devauchelle-Pensec V, Saraux A, Pers JO. Anti-B lymphocyte immunotherapy is associated with improvement of periodontal status in subjects with rheumatoid arthritis. J Clin Periodontol. 2015;42(9):817-23.

30. Marotte $\mathrm{H}$. Tooth-brushing: an impact on rheumatoid arthritis. Joint Bone Spine. 2016;83(6):619-21.

31. Marotte H. Non-surgical periodontal disease: a new treatment for rheumatoid arthritis? Joint Bone Spine. 2020;87(1):1-3.

32. Marotte $H$. Non-surgical periodontal disease to treat rheumatoid arthritis after selection of the right patients. Rheumatology (Oxford). 2020;59(5): 928-9.

33. Cosgarea R, Tristiu R, Dumitru RB, Arweiler NB, Rednic S, Sirbu Cl, et al. Effects of non-surgical periodontal therapy on periodontal laboratory and clinical data as well as on disease activity in patients with rheumatoid arthritis. Clin Oral Investig. 2019;23(1):141-51. https://doi.org/10.1007/ s00784-018-2420-3. Epub 2018 Mar 27. PMID: 29589156.

34. Kaushal S, Singh AK, Lal N, Das SK, Mahdi AA. Effect of periodontal therapy on disease activity in patients of rheumatoid arthritis with chronic periodontitis. J Oral Biol Craniofac Res. 2019;9(2):128-32. https://doi.org/10. 1016/j.jobcr.2019.02.002.

35. Okada M, Kobayashi T, Ito S, Yokoyama T, Abe A, Murasawa A, et al. Periodontal treatment decreases levels of antibodies to Porphyromonas gingivalis and citrulline in patients with rheumatoid arthritis and periodontitis. J Periodontol. 2013;84(12):e74-84. https://doi.org/10.1902/jop. 2013.130079. Epub 2013 May 23. PMID: 23701010. 
36. Monsarrat P, Vergnes JN, Cantagrel A, Algans N, Cousty S, Kémoun P, et al. Effect of periodontal treatment on the clinical parameters of patients with rheumatoid arthritis: study protocol of the randomized, controlled ESPERA trial. Trials. 2013;14:253. https://doi.org/10.1186/1745-6215-14-253. PMID: 23945051; PMCID: PMC3751435.

37. Monsarrat P, Fernandez de Grado G, Constantin A, Willmann C, Nabet C, Sixou M, Cantagrel A, Barnetche T, Mehsen-Cetre N, Schaeverbeke T, Arrive E, Vergnes JN, ESPERA Group. The effect of periodontal treatment on patients with rheumatoid arthritis: the ESPERA randomised controlled trial. Joint Bone Spine. 2019;86(5):600-9. https://doi.org/10.1016/j.jbspin.2019.02 006. Epub 2019 Feb 26. PMID: 30822490.

\section{Publisher's Note}

Springer Nature remains neutral with regard to jurisdictional claims in published maps and institutional affiliations.

Ready to submit your research? Choose BMC and benefit from:

- fast, convenient online submission

- thorough peer review by experienced researchers in your field

- rapid publication on acceptance

- support for research data, including large and complex data types

- gold Open Access which fosters wider collaboration and increased citations

- maximum visibility for your research: over $100 \mathrm{M}$ website views per year

At BMC, research is always in progress.

Learn more biomedcentral.com/submissions 